\title{
Metformin intoksikasyonuna sekonder gelişen akut böbrek hasarı ve laktik asidoz
}

\author{
Acute renal failure and lactic acidosis seconder to metformin intoxication
}

Halil Aydar, Neslihan Tezcan, Rüya Mutluay

Gönderilme tarihi:22.03.2021

Kabul tarihi:27.10.2021

\section{Öz}

Metformin biguanid sınıfına ait bir oral antidiyabetik ajandır. Hepatik glukoneogenezi inhibe ederek glukoz üretimini azaltır; periferal dokularda insulin duyarlıığını düzeltir. Bilinen en korkulan yan etkisi laktik asidoz ve akut böbrek hasarıdır. Metformin gerek ucuz olması gerek ise diyabet tedavi kılavuzlarında ilk sıralarda yer alması nedeniyle diyabet tanılı hastalarda oldukça sık kullanılan bir ilaçtır. Bu olgu sunusunda bilinen hipertansif bir hastada yeni diyabet tanısı ile metformin tedavisine başlanmasından bir kaç ay sonra intihar amaçlı yüksek doz metformin alımına sekonder gelişen laktik asidoz ve akut böbrek hasarlı bir olgu anlatılmaktadır.

Anahtar kelimeler: Metformin intoksikasyonu, akut böbrek hasarı, laktik asidoz.

Aydar H, Tezcan N, Mutluay R. Metformin intoksikasyonuna sekonder gelişen akut böbrek hasarı ve laktik asidoz. Pam Tıp Derg 2022;15:379-382.

\begin{abstract}
Metformin is a oral antidiabetic drug being class of biguanid. It reduces hepatic glucose production by inhibiting gluconeogenesis, improves peripheral insulin sensivity. The well known serious side effects are acute renal failure and lactic asidosis. Metformin is the most commonly prescribed drug because of its cost-effectiveness and existing in first line theraphy in guidelines for type 2 diabetes mellitus. We report a case a patient with known hypertension and new diagnosis diabetes mellitus, presenting acute renal failure and lactic acidosis seconder to taking overdose metformin in suicide attempt.
\end{abstract}

Key words: Metformin intoxication, acute renal failure, lactic acidosis.

Aydar $\mathrm{H}$, Tezcan N, Mutluay R. Acute renal failure and lactic acidosis seconder to metformin intoxication. Pam Med J 2022;15:379-382.

\section{Giriş}

Metformin biguanid sınıfına ait bir oral antidiyabetik ajandır. Kan glukoz seviyesini düşürmesindeki ana mekanizma glukoneogenezisi inhibe ederek hepatik glukoz üretimini azaltmasıdır [1]. Periferik dokularda glukoz alımını ve kullanımını arttırmanın yanı sıra özellikle kas dokuda insulin duyarlılığını düzeltici yönde etkileri de mevcuttur [2]. Metformin son yıllarda kan şekerini düşürücü etkisi dışında gösterdiği pleiotropic etkileri nedeniyle polikistik over sendromu, nonalkolik yağlı karaciğer hastalığı ve premature puberte gibi pek çok farklı durumda kullanılır olmuştur [2-5]. Pekçok endikasyonla dünya üzerinde yaygın kullanımı olan metforminin gastrointestinal sorunlar ve B12 vitamin eksikliği başlıca sık görülen yan etkileridir. En korkulan yan etkileri ise nadir karşılaşılan laktik asidoz ve akut böbrek hasarıdır. Biguanidler içerisinde en eskilerinden biri olan phenforminle karşılaştırıldığında metformine bağlı laktik asidoz sıklığının diğerine göre 20 kat daha az olduğu bilinmektedir [6, 7]. Ayrıca metformin kullanımına dair bu komplikasyonun böbrek ve karaciğer rezervi azalmış olanlar, ileri yaşlı bireyler, hemodinamisi bozulmuş hastalar ve ciddi kalp yetmezliği olan hastalarda artmakta olduğu da bilinmektedir [6]. Bu nedenle de glomerular filtrasyon hızı (GFR) azalan bireylerde metformin kullanımının her kontrolde tekrar değerlendirilmesi, ileri böbrek yetmezliği olması halinde kullanılmaması ve dozajının eGFR'ye gore titre edilmesi önerilmektedir [2, 8]. Laktik asidoz arteryel kan ph'nın 7,35'in altında, laktat seviyesinin ise $5 \mathrm{mmol} / \mathrm{L}$ 'nin üzerinde olmasıyla karakterize hayatı tehdit

Halil Aydar, Uzm. Dr. Eskişehir Osmangazi Üniversitesi Tıp Fakültesi, Nefroloji Bilim Dalı, Eskişehir, Türkiye, e-posta: halil3634@gmail.com (https:// orcid.org/0000-0003-4431-3482) (Sorumlu Yazar)

Neslihan Tezcan, Uzm. Dr. Eskişehir Osmangazi Üniversitesi Tıp Fakültesi, Nefroloji Bilim Dalı, Eskişehir, Türkiye, e-posta: neslihanberic@hotmail. com (https://orcid.org/0000-0002-6525-6088)

Rüya Mutluay, Doç. Dr. Eskişehir Osmangazi Üniversitesi Tıp Fakültesi, Nefroloji Bilim Dalı, Eskişehir, Türkiye, e-posta: ruyamutluay@yahoo.com (https://orcid.org/0000-0002-7159-0082) 
eden bir durumdur $[8,9]$. Tip A ve tip B olmak üzere ikiye ayrılan laktik asidozda tip $A$ artmış hipoksi nedeniyle glikoliz yoluyla biriken laktattan kaynaklanırken, metfromine bağlı görülen laktik asidozla (MALA) da ilişkili olan tip $B$ ise üretimi artan laktik asidozun klirensinde azalma ile karakterizedir. Metformin ilişkili laktik asidozun mekanizması metforminin dokulardaki mitokondriyal oksidatif fosforilizasyonu inhibe ederek laktatın birikmesine ve klirensinde azalmaya neden olmasıdır [6]. Metformin ilişkili laktik asidoz sıklığı 1-9 vaka/100.000 hasta yılıdır ve mortalite oranı \%30-50'dir [10].

\section{Olgu}

Ellibir yaşında 7 yıldır hipertansiyonu ve yeni tanı diyabetes mellitusu (DM) olan, bir süre önce de depresif semptomlar nedeniyle antidepresif tedavi eklenen hasta acil servise intihar amaçlı 39 tablet 1000 mg metformin, 27 tablet $5 \mathrm{mg}$ aripiprazol, 25 tablet $25 \mathrm{mg}$ ketiapin, 27 tablet $50 \mathrm{mg}$ sertralin içtikten yaklaşık 12 saat sonra yakınları tarafından bilinci kapalı olarak getirilmiş. Özgeçmişinde yaklaşık 8 yıldır düzenli valsartan+hidroklorotiazid ve 3 aydır metformin 2x850 mg tablet kullandığı, nefrolitiazis nedeniyle bir kaç kez üroloji polikliniğine başvurusu olduğu ancak bilinen böbrek disfonksiyonu olmadığı öğrenildi. Beş yıl öncesine ait kreatinin değerinin 1,12 mg/dL olarak ölçüldüğü bilgisi kayıtlardan gözlemlendi. Fizik muayenesinde; bilinç bulanık, nonoryante, nonkoopere, glaskow koma skalası 9, kan basıncı 60/42 mmHg, kalp hızı 95/dakika idi. Hastanın acil servisteki ilk geliş laboratuar değerlerinde kan üre azotu (BUN) 22,3 mg/ $\mathrm{dL}$, kreatinin 2,32 mg/dL, sodyum $143 \mathrm{mEq} / \mathrm{L}$, potasyum 5,2 mEq/L, klor $105 \mathrm{mEq} / \mathrm{L}$, venöz kan gazında $\mathrm{pH} 7,05$, bikarbonat $10 \mathrm{mmol} / \mathrm{L}$, laktat 13,6 mmol/L, $\mathrm{pO}_{2} 46 \mathrm{mmHg}, \mathrm{pCO}_{2} 40$ $\mathrm{mmHg}$, anyon açığı $28 \mathrm{mEq} / \mathrm{L}$ idi. Hemogram ve karaciğer fonksiyon testleri ile idrar tahlili normaldi. Anurik ve laktik asidozu olan hasta ilk olarak acil serviste hemodiyalize (HD) alındı. Daha sonra yoğun bakıma yatırılan hastanın takibinde 2 gün sure ile sürekli renal replasman tedavisi (CRRT) yapıldığı öğrenildi; bu tedavinin sonlandırılmasından 24 saat sonra hastanın böbrek fonksiyonlarındaki bozukluğun devam etmesi ve hipervoleminin eklenmesi nedeniyle hasta yeniden değerlendirilerek aralıklı HD tedavisine başlandı ve hastanın idrar miktarının artması ve böbrek fonksiyonlarının stabil seyretmesine kadar da birkaç seans devam edildi. Takiplerinde idrar çıkışı artan, böbrek fonksiyonları kısmen regrese olan ve asidozu düzelen hasta nefroloji servisine alındı. Hastanın servis takiplerinde BUN $30 \mathrm{mg} / \mathrm{dL}$, kreatinin 1,4 $\mathrm{mg} / \mathrm{dL}$ 'ye kadar iki hafta içinde geriledi. Hasta psikiyatri kliniğine ileri tedavi için devredildi ve iki hafta bu bölümdeki hospitalizasyonun ardından taburcu edildi. Hastanın gelişinden taburcu oluşuna kadar geçen süredeki laboratuar değerleri Tablo 1'de özetlenmiştir.

Tablo 1. Hastanın BUN, kreatinin, kan gazı seyri ve uygulanan RRT

\begin{tabular}{lllllll}
\hline & $\begin{array}{l}\text { BUN } \\
\mathrm{mg} / \mathrm{dL}\end{array}$ & $\begin{array}{l}\text { KREATiNiN } \\
\mathrm{mg} / \mathrm{dL}\end{array}$ & $\mathrm{Ph}$ & $\begin{array}{l}\text { BiKARBONAT } \\
\mathrm{mmol} / \mathrm{L}\end{array}$ & $\begin{array}{l}\text { LAKTAT } \\
\mathrm{mmol} / \mathrm{L}\end{array}$ & RRT durumu \\
\hline 29.01.2021 & 22,3 & 2,3 & 7,08 & 9,6 & 12 & HD \\
30.01 .2021 & 20,5 & 2,2 & 7,18 & 11,7 & 15 & CRRT \\
31.01 .2021 & 26,4 & 2,8 & 7,42 & 24 & 3,5 & CRRT \\
01.02 .2021 & 46,4 & 4,78 & 7,48 & 26 & 1,8 & HD \\
02.02 .2021 & 64,7 & 6,85 & 7,43 & 26 & 2,1 & HD \\
03.02 .2021 & 45,1 & 5,59 & 7,43 & 22 & 2,1 & - \\
15.02 .2021 & 49,8 & 4,32 & 7,47 & 22,8 & 1,2 & - \\
01.03 .2021 & 37.2 & 1,75 & 7,42 & 22 & 1,2 & - \\
15.03 .2021 & 32,3 & 1,55 & 7,40 & 24 & 1,4 & - \\
\hline
\end{tabular}




\section{Tartışma}

Tip 2 Diyabet tedavisinde herhangi bir kontraendikasyon olmadığında ilk sıralarda tercih edilen metforminin en korkulan yan etkisi laktik asidoz ve akut böbrek hasarıdır. Yarı ömrü yaklaşık 4-8 saat olan ve \%90'ı renal yolla elimine edilen metforminin sağlıklı böbreklere sahip bireylerde bu komplikasyona sık olarak yol açmadığı da bilinmektedir ki dünya üzerinde yaygın olarak kullanılmaktadır [1]. Metformin laktik asidoz üretimini arttırıp, klirensini azaltarak laktik asidoza neden olmaktadır; literatürde metformin tedavisi esnasında ya da bir sebeple yüksek doz alınması sonrasında gelişen akut böbrek hasarı ve laktik asidozun sürekli veya aralıklı renal replasman tedavileriyle (RRT) düzeldiğine ya da mortalitenin oluştuğuna dair tek veya seri halinde az sayıda vaka bildirimleri mevcuttur [911]. Ayrıca yüksek doz metilprednizolon tedavisi ile RRT intiyacı olmaksızın düzeltilebilen bir pediatrik vaka bildirisi de mevcuttur [12]. Bu son literatürde bahsedilen pediatrik vaka intihar amaçlı yüksek doz metformin alımından sonra laktik asidoz ile prezente olmayıp orta düzeyde bir renal disfonksiyon tablosu ile kendini göstermiş ve vakada ilaca bağlı interstisyel nefrit düşünülmüştür [12]. Metforminin direkt nefrotoksik etkisinin olmadığı; glukoneogenezi inhibisyon sonucunda biriken laktatın akut böbrek hasarına yol açtığı düşünülmektedir [1]. Azalmış glomerular filtrasyon hızı olan hastalarda bu yan etkinin daha fazla görülebileceğini beklemekle birlikte glomerular filtrasyon hızı normal olanlarda da terapötik dozda metformin kullanımı ile nadir de olsa bu komplikasyona dair bildirimler yapılmıştır. Arroyo ve ark. [11] 2006 ile 2010 yılları arasında metformin tedavisi alırken akut böbrek hasarı gelişen vakaları taradıklarında toplam 29 vakada bu komplikasyonun gelişmiş olduğunu; vakaların onikisini GFR'si 60 ml/dk'nın üzerinde olan hastaların oluşturduğunu ve bu grubun diğer gruba göre daha fazla RRT intiyacının olduğunu rapor etmişlerdir. Bizim olgumuz da daha önceye ait elimizde çok düzenli kayıtlar olmasa da bilinen ciddi bir böbrek hastalığı anamnezi vermemekte idi. Suisid amacı ile oldukça yüksek dozda metformin ve beraberinde başka ilaçların da kullanımı söz konusu idi ve bu ilaçların birbirlerinin etkilerini değiştirebilme intimalleri de vardı. Ne yazık ki hastanın içmiş olduğunu beyan ettiği ilaçların düzeylerine bakabilme şansımız yoktu. Eğer bu ilaçların kan düzeylerini düzenli olarak monitörize edebilme imkanımız olsaydı metformin düzeyi ve laktik asidoz ile böbrek hasarı arasındaki ilişkiyi daha net takip edebilme şansımız olabilirdi.Hastanın metformin dışında içtiği diğer ilaçlarda ise laktik asidoz riski bulunmamaktaydı. Literatürde de görüldüğü üzere metformin sonrası gelişen laktik asidoz ve akut böbrek hasarı varlığında destek tedavisi ve endikasyon dahilinde RRT önerilmekte olup; biz de hastamıza hastaneye başvurusundan intiyacı kalmayana kadar RRT desteği vermek zorunda kaldık. Şunu ifade etmek ve tartışmak gerekir ki sunduğumuz hastada belki RRT ihtiyacı erken ortadan kalktı ancak böbrek fonksiyonlarındaki düzelme çok yavaş oldu. Bunun da sebepleri olarak hastanın ilaç sonrası hastaneye başvurusunun 12 . saatten sonra olması, metformin dışında başka ilaçların da yüksek dozda alınmış olmasına bağlı gelişen ilaç etkişimleri ve yan etkilerin kuvvetlenmesi ve belkide hastanın bazalde var olan rezidüel renal fonksiyon kaybı olarak düşünüldü.

Sonuç olarak, metformin toplumda başlıca diyabet olmak üzere pek çok endikasyonla yaygın olarak kullanılmakta olan bir ilaç olup takip ve tedavi sırasında laktik asidoz ve akut böbrek hasarı ile karşılaşılabilir. Bu durum ilaç dozlarına ve rezidüel renal fonksiyonlara bağlı olmaksızın da görülebilir ve mortalite oranı da ne yazık ki oldukça yüksektir. Metformin kullanan hastalar bu bilgiler ışığında takip edilmeli; takipleri esnasında böyle bir durum gelişmesi halinde imkanlar dahilinde RRT dahil tüm destekleyici tedaviler endikasyon dahilinde uygulanmalıdır.

Çıkar ilişkisi: Yazarlar çıkar ilişkisi olmadığını beyan eder.

\section{Kaynaklar}

1. Momenzadeh M, Lakkakuka BVKS. Metformin induced acute kidney injury; a systematic review. J Nephropharmacol 2021;10:13. https://doi. org/10.34172/npj.2021.13

2. Corremans R, Vervaet BA, D'haese PC, Neven E, Verhulst A. Metformin: a candidate drug for renal diseases. Int J Mol Sci 2019;20:42. https://doi. org/10.3390/ijms20010042

3. Lashen $\mathrm{H}$. Role of metformin in the management of polycystic ovary syndrome. Ther Adv Endocrinol Metab 2010;1:117-128. https://doi. org/10.1177/2042018810380215 
4. Li Y, Liu L, Wang B, Wang J, Chen D. Metformin in nonalcoholic fatty liver disease: a systematic review and meta-analysis. Biomed Rep 2013;1:57-64. https://doi. org/10.3892/br.2012.18

5. Ibanez L, Ong K, Valls C, Marcos MV, Dunger DB, De Zegher $\mathrm{F}$. Metformin treatment to prevent early puberty in girls with precocious pubarche. J Clin Endocrinol Metab 2006;91:2888-2891. https://doi.org/10.1210/ jc.2006-0336

6. DeFronzo R, Fleming GA, Chen K, BicsakTA. Metforminassociated lactic acidosis: current perspectives on causes and risk. Metabolism 2016;65:20-29. https:// doi.org/10.1016/j.metabol.2015.10.014

7. Chan NN, Brain HP, Feher MD. Metformin-associated lactic acidosis: a rare or very rare clinical entity? Diabet Med 1999;16:273-281. https://doi.org/10.1046/j.14645491.1999.00006.x

8. Inzucchi SE, Lipska KJ, Mayo H, Bailey CJ, McGuire DK. Metformin in patients with type 2 diabetes and kidney disease: a systematic review. JAMA 2014:312:26682675. https://doi.org/10.1001/jama.2014.15298

9. Angioi A, Cabiddu G, Conti M, et al. Metformin associated lactic acidosis: a case series of 28 patients treated with sustained low-efficiency dialysis (SLED) and long-term follow-up. BMC Nephrology 2018;19:77. https://doi.org/10.1186/s12882-018-0875-8

10. Kinoshita H, Yanai M, Ariyoshi K, Ando M, Tamura R. A patient with metformin-associated lactic acidosis successfully treated with continuous renal replacement theraphy: a case report. J Med Case Rep 2019;13:371. https://doi.org/10.1186/s13256-019-2311-5

11. Arroyo D, Melero R, Panizo $\mathrm{N}$, et al. Metforminassociated acute kidney injury and lactic acidosis. Int J Nephrol 2011;2011:749653. https://doi. org/10.4061/2011/749653

12. Kocaoğlu Ç, Özel A. Metformin intoksikasyonuna bağlı akut böbrek yetmezliği: olgu sunumu. J Turk Soc Intensive Care 2018;16:76-78. https://doi.org/10.4274/ tybd.26818

Hasta onamı: Hastadan bilimsel faaliyet için aydınlatılııs sözlü ve yazılı onam alınmıştır.

\section{Yazarların makaleye olan katkısı}

R.M. çalışmanın ana fikrini kurgulamıştır; H.A. ve N.T. yazıyı düzenlenmiş son haline getirmişlerdir; yazının son hali R.M. tarafından gözden geçirilmiş tüm yazarlar tarafından onaylanmıştır. 